\title{
Über die Notwendigkeit eines zweiten Vorworts
}

20 Jahrgänge der "Sportwissenschaft" liegen nun vor, mit Ausnabme des ersten Jabrganges 1971 mit jeweils vier Heften. In allen Ausgaben hat der geschäftsführende Herausgeber Ommo Grupe eine Einleitung " $\mathrm{Zu}$ diesem Heft" geschrieben, auch zu diesem dem letzten Heft des 20. Jabr. gangs. Wenn, vermutlich zum ersten Mal überhaupt, ein zweites Vorwort binzugefügt wurde, von dem Ommo Grupe nichts wußte, dann gibt es dafür gute Gründe.

- Der erste ist biographischer Art: Im Verlaufe des letzten Quartals 1990 ist Ommo Grupe 60 Jabre alt geworden. 20 Jabre lang, und das ist immerbin genau ein Drittel seiner ganzen Le. benszeit, hat er sich mit Engagement und mit großem zeitlichen Aufwand für seine „Sportwissenschaft ${ }^{*}$ eingesetzt, 78 Vorwörter legen Zeugnis ab. Die Herausgeberorganisationen $\operatorname{der}$ Ausscbuß Deutscher Leibeserzieber, der Deutsche Sportbund und das Bundesinstitut für Sportwissenschaft - und seine Kolleginnen und Kollegen im In-und Ausland danken Ommo Grupe für diese beispiellose Leistung.

- Der zweite Grund betrifft die inbaltlich-strukturelle Seite seiner Herausgebertätigkeit: Grupes zwölf Seiten lange Einleitung in das Heft 197V1 war Standortbestimmung und Programm zugleich; die bis beute andauernde Zitierung von Feststellungen aus dieser Einleitung belegt ibre Aktualität und damit die Richtigkeit der Grupeschen Einschätzung. Viele folgende. Einleitungen hat er benutzt, um sein Wissen und seine Wünsche, aber auch seine Sorgen und Befürchtungen auszudrücken. So gingen diese sogenannten Vorzërter bäufig über die Einfübrung in die einzelnen Sachthemen der Hefte binaus, mit seiner Beurteilung und Folgenabschätzung der deutsch-deutschen Vereinigung in der Sportwissenschaft liegt in diesem Heft ein weiterer nachprüfbarer Beweis vor.

- Und schließlich drittens: Dreißig Kolleginnen und Kollegen baben den 60. Geburtstag von Ommo Grupe zum Anlaß genommen, in dreißig Themen „Für einen besseren Sport ... . (Titel) ibre Überlegungen vorzutragen. $H$. Gabler und $U$. Göhner als die verantwortlichen Her. ausgeber des Bandes baben bei allen Autoren festgestellt, daß sie die Bitte zur Mitarbeit als eine Herausforderung angesehen baben. Und so bat uns alle Ommo Grupe eigentlich immer angespornt und gefordert, so wie er sich selbst auch immer belastet und nie geschont bat. Die gesellschaftliche Relevanz und Akzeptanz des Sports war ihm, wie es die Frankfurter Allgemeine Zeitung jüngst erneut herausstellte, das Hauptanliegen über alle Einzelthemen und Sachanliegen binaus, „Sport als Kultur “ hat Ommo Grupe seine jüngste Monograpbie über. schrieben und dabei unterstrichen, daß auch er den Sport als eine der ganz großen sozialen Erscheinungen und Bewegungen am Ende dieses Jabrhunderts siebt. Wir alle sollten ibm ein weiteres Geburtstagsgeschenk macben, indem wir seine und unsere "Sportwissenschaft" noch mehr als bisher durch Mitwirken, Mitdenken und Kritisieren in ibrer Zielsetzung unterstüt. zen.

August Kirsch 